\title{
Managing Knowledge of Stakeholders' Interests towards Sustainable Development
}

\author{
Astrie Krisnawati \\ Institut Manajemen Telkom, Indonesia \\ astrie_k@yahoo.com
}

\begin{abstract}
This study aims to find a linkage between Knowledge Management and Sustainable Development through implementation of Triple Bottom Line concept. It is a conceptual paper that applies literature review for proposing a conceptual model as the finding of this study. The model describes how a company should manage the knowledge to maintain good relationships with all of its stakeholders in order to achieve sustainable development in creating mutual benefit value for the good of all parties. This study identifies who the company's stakeholders are, what their interests, and what knowledge the company should have and manage to fulfill the stakeholders' interests towards sustainability. The conceptual model needs to be examined empirically. A case study implementing this model into a certain company can be considered as the further research.
\end{abstract}

Keywords: Knowledge Management, Stakeholders, Sustainable Development, Sustainability, Triple Bottom Line

\section{Introduction}

There is a major paradigm shift in current business. Within the fierce competition, innovation is absolutely required in any organizations. A company that is able to create more value of its products and services than its competitors is the one that can master the market. The most powerful thing to survive is no longer financial capital, but intellectual capital. Stewart (1997) defines intellectual capital as an accumulative of everything known by everybody in a company that can contribute competitive advantages to the company. Information extremely becomes valuable and worthwile for everybody in this era. Then it is now called as knowledge-based economy era. Leydesdorff (2006) states that information can be firstly communicated and codified into a meaning, then a meaning can be further codified in the next step to become knowledge. Thus, knowledge can be supposed as a meaning which creates a difference. It is also influenced by the social system that changes in an uncertainty.

Implementing rapid improvement of technology for innovation is a way to improve economic wealth of a nation. Korea is the best sample of this matter. Knowledge is an essential matter in Korea as it has achieved the high level of development by harnessing knowledge effectively in its economic activities. Based on data defined by OECD (2000), knowledge-based industries currently record for $50,4 \%$ of value added in business sector. It ranges from $31,4 \%$ in Iceland as the lowest to $58,6 \%$ in Germany as the highest. In Korea, knowledge-based industries contribute $40,3 \%$ of value added in the business sector with knowledge-based manufacturing records a major share of GDP in overall. The ultimate context of knowledge-based economy is the result of intellectual capital. It is important to ensure that the knowledge-based economy is able to create valuable and effective outcomes that can be identified. Thus, managing a knowledge-based economy means managing the circumtance to contribute positive outcomes within the relationship between several parties. "Knowledge is a system of phenomenological qualities that are emergent properties of relations that interplay with (and within) individuals, groups, time (history) and places (including the physical objects in places). The essential animating elements of knowledge are found in its social, cultural and tacit processes" (Rooney et al., 2003).

Every company always deals with relationship among many parties in running its business. Solomon (2007) explains that currently, companies become larger and more complex, so that the impacts of their activities also become more pervasive on society. They are strongly demanded to be responsible for discharging accountability to many more sectors of society rather than simply to their shareholders. It is in accordance with the situation previously figured out by Frederick, Davis, and Post (1998) that there is no vacuum circumtance of where today's business takes place. Business firms cannot avoid to face complicated social problems, controversies, and threatening components of the social environments in which they operate. Inharmonious relations with stakeholders can be harmful for the company to 
continue its business. Therefore, it is necessary for every company to master the proper knowledge to maintain good relationships with all of its stakeholders in order to attain the sustainable development. In terms of sustainable development, UK Government has taken priorities for action of sustainable consumption and production; climate change and energy issues; natural resources protection and environmental improvement; and sustainable communities (Blewitt,2008). It shows that current business situation requires every company to be responsible not only economically, but also socially and environmentally.

\section{Literature Review}

Knowledge Management: In the knowledge-based economy era, the existence of knowledge in every organization is a must. Knowledge is absolutely required in all companies to build their competitive advantages in order to survive within the harsh competition. Many companies fail in the competition not because of their lack of resources, but it is due to their failure in managing knowledge. They fail to manage individuals' knowledge to be collected to become organizational knowledge, as well as they fail to transform tacit knowledge to become explicit knowledge within the organization. Cheung et al. (2007) state that, "Knowledge management can lead to a way for an organization to "know what they know and what they do not know', the need to share, retain and reuse the knowledge". According to Nguyen and Mohamed (2011), knowledge management is both a process and a goal at the same time. Therefore, knowledge management emphasizes in deploying knowledge to attain advantages for the organization. Then knowledge also needs proper systems to capture critical knowledge, store knowledge in database, and enable people to get access of the knowledge in order to give benefit for the organization (Ergazakis, et al., 2005).

Stakeholder Theory: 'Stakeholders' is defined as those parties who affect and are affected mutually in a company's business activities (Solomon,2007). March and Simon (1958) depict the pattern of relationship between a company and its stakeholders as a reciprocity that stakeholders contribute subscriptions for the company in accordance with their efforts to fulfill their interests, then the company should reward them some benefits. The concept of Triple Bottom Line - coined by Elkington (1998) - is the development of stakeholder theory. It figures the synergy of three aspects, i.e. profit, people, and planet, in business activities. The point of this concept is that every business must be oriented in economic achivement to gain profit but the efforts of attaining profit must be in accordance with its responsibility in social matters to respect people in society arround the business takes place. It must also concern with the sustainability of ecological environment in this planet. Those three aspects can be defined further into the company's stakeholders, as follow:

Profit: This aspect deals with the interest of a company's shareholders in which they expect to gain wealth as the return of their investment in business run by the company.

People: This aspect deals with society inside and arround the business. It includes employees, customers, suppliers, creditors, competitors, communities, and government.

Planet: This aspect deals with ecological environment where the company operates and takes natural resources for its production.

Sustainable Development: Sustainable development is defined by World Commission on Economic and Development (WCED, 1987) as "develoment that meets the needs of the present without compromising the ability of future generations to meet their own needs." This definition emphasizes the concept in the balance between present and future dimensions. It also takes into account the combination of short-term and long-term developments (Gechev, 2005). While Maples (2005) defines sustainable development as a concept of hybrid between innovation and conservation. It is about doing innovation to respond the current rapid changes while conserving socio-economical systems as well as ecosystems in balance.

\section{Methodology}

It is a conceptual paper that applies literature review and qualitative approach to formulate a conceptual model as the result of this study. The model is built to classify who the company's common stakeholders are, to identify what the stakeholders' needs and interests, to find out what knowledge is needed to fulfill the stakeholders' interests, and to answer how to manage the knowledge in order to reach the company's sustainable development. 
Figure 1: The pattern of relationship between a company and its stakeholders (Krisnawati, 2013)

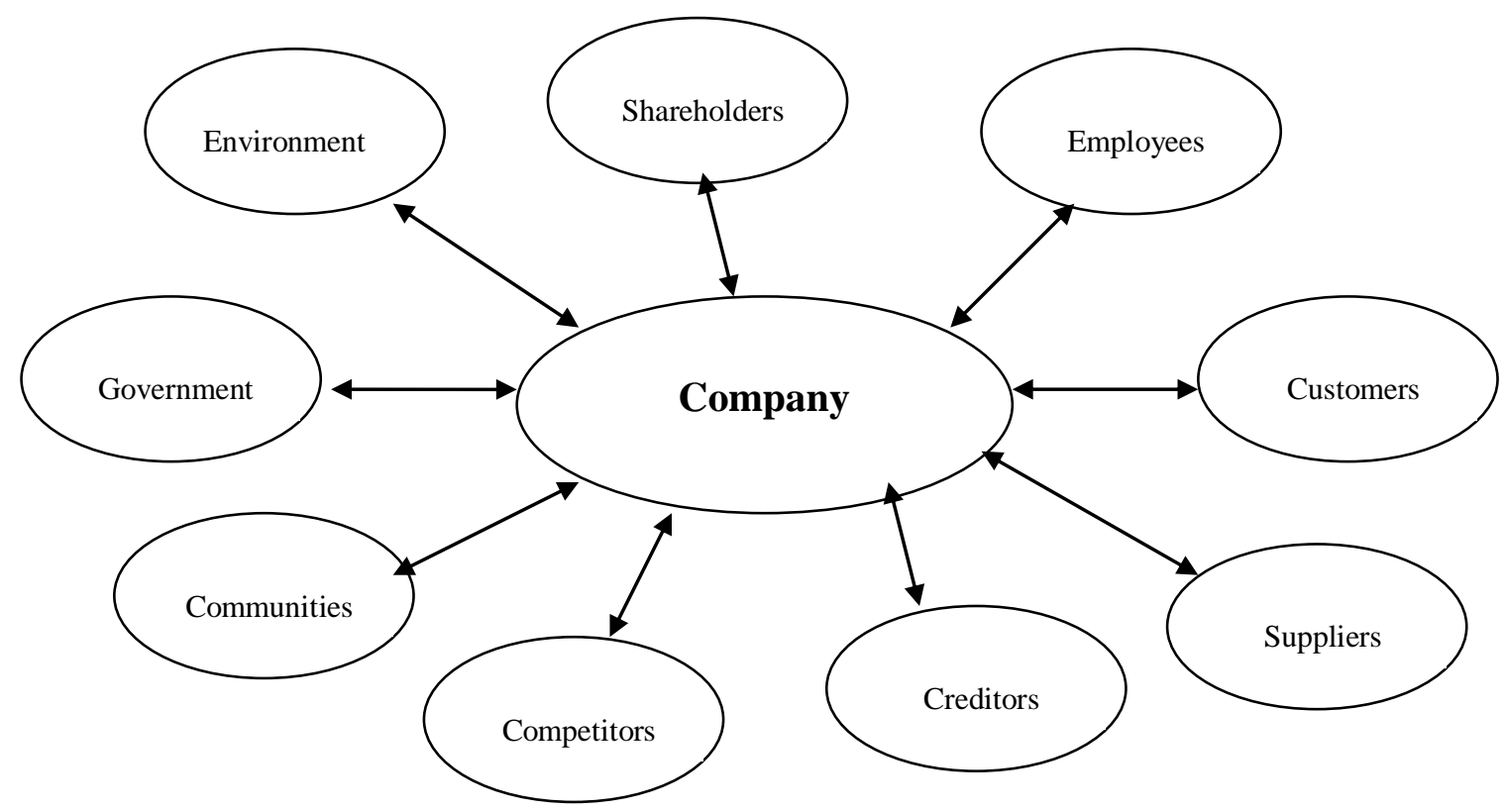

\section{Results and Discussion}

Knowledge is no longer a complementary thing of an organization, instead, it must be supposed as an important asset. As an asset, it must be able to be identified, measured, calculated, stored, shared, retained, and reused for the long term. Eventhough the presence of individuals in a company is perishable, but the knowledge of those individuals should be able to be kept henceforth in the organization. When an individual resigns from a company, his or her knowledge must keep existing in the company to be reused by the next generations in the future. This is the concept of sustainability. The ability to manage knowldge to make it keep existing and can be utilized for longer term is a big effort to reach sustainable development of a company.

Robinson et al. (2006) create an analogy of a tree to figure out how important the organization's knowledge is. They explain that emphasizing business' goals in only profit matters for the sake of shareholders' wealth is like short-term harvesting of the fruits of success. While doing business by building knowledge asset to meet stakeholders' value is a long-term oriented effort. This concept combines hard physical (tangible) assets and soft knowledge (intangible) assets for the sake of value creation. Components of hard physical asets are visible, e.g. debt equity. While the componants of soft knowledge assets are invisible, it is called as intellectual capital.

The comprehensive knowledge to attain sustainability is knowledge of stakeholders' interests. By having knowledge of stakeholders' interests comprehensively, a company can have a clear direction for what it should do in running its business properly. In running its business, a company depends on resources derived from its stakeholders to support its sustainability. Then the main goal of business in every company is no longer simply for the sake of shareholders' wealth, but entirely for the welfare of all stakeholders. Therefore, it is significantly crucial for a company to identify the interests of all stakeholders and to manage the critical knowledge. Critical knowledge is the knowledge required to be held by a company to fulfill the stakeholders' interests. It is figured out in the matrix model as follow: 
Table 1: Matrix Model of Stakeholders' Interests and the Critical Knowledge

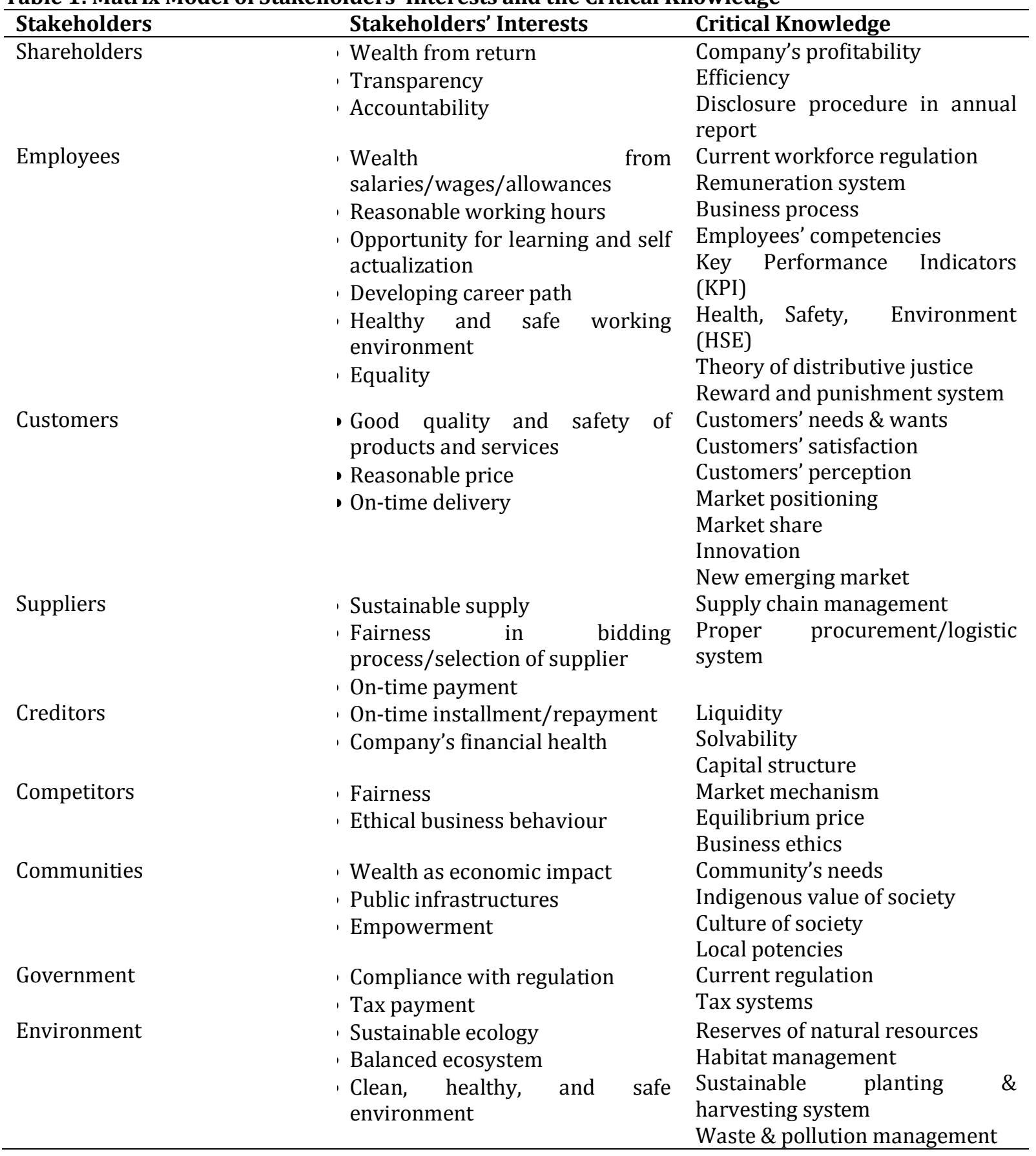

Table 1 shows who the company's stakeholders are and what their interests. The table lists the needs and wants of each stakeholder must be fulfilled by the company. It also points what critical knowledge must be possessed by the company to fulfill and satisfy Snyman and Kruger (2004) state that knowledge is a strategic resource of a company. It has a strategic role to enable the efforts in formulating strategies to win. Knowledge also has a strong power to positively influence and enable the business strategy. It is important to reach a good synergy between business strategy and knowledge management strategy. To achieve sustainable development, a company should implement the best practice of Knowledge Management strategy. The knowledge must be integrated into vision, missions, strategy, and also be included within the whole business process of a company through an integrated information system. The knowledge must be realized and applied by all the company's members. Not only to be implemented by the top level of management, it must also be able to be cascaded to the shop floor.

Aligning sustainability with core strategy is one way to speed a company's journey. The strategy should be driven by top leadership and overseen by the board, then implemented by all members. Grayson (2011) 
state that the strategy also should be integrated into all business functions and strategic business units, involving suplliers, employees and customers. It is important to bring through the implementation of strategy in a company by developing knowledge management, training and attaching the wider stakeholders, establishing partnerships and collaborations, and developing sustainability team for internal change-management and continuous improvement. A study done in Marks and Spencer shows that running business based on trust-based relationships with employees, long-term shared destiny with suppliers and customers, inclusive culture, and innovation will demonstrate a continuous progress.

Integration of all stakeholdrs' interests is the main issue of sustainability. Pirnea, Olaru, and Moisa (2011) mention that a company's sustainable success depends on its ability to fulfill its stakeholders' needs and expectations within the long term period and balanced perspective. A company can attain its sustainable success by implementing effective management, being aware of environmental issues, learning, applying proper improvements, and creating innovations. To achieve proper improvements, we need to align the vision, mision, objectives, and strategies of a company. Then we have to identify the critical knowledge required to meet stakeholders' interests and the existing knowledge owned by the company to find the gap that must be improved in order to reach sustainable development. Below is a model of integration between company's strategies, stakeholders' interests and knowledge management towards sustainable development:

Figure 2: Model of Integration between Company's Strategies, Stakeholders' Interests, and Knowledge Management

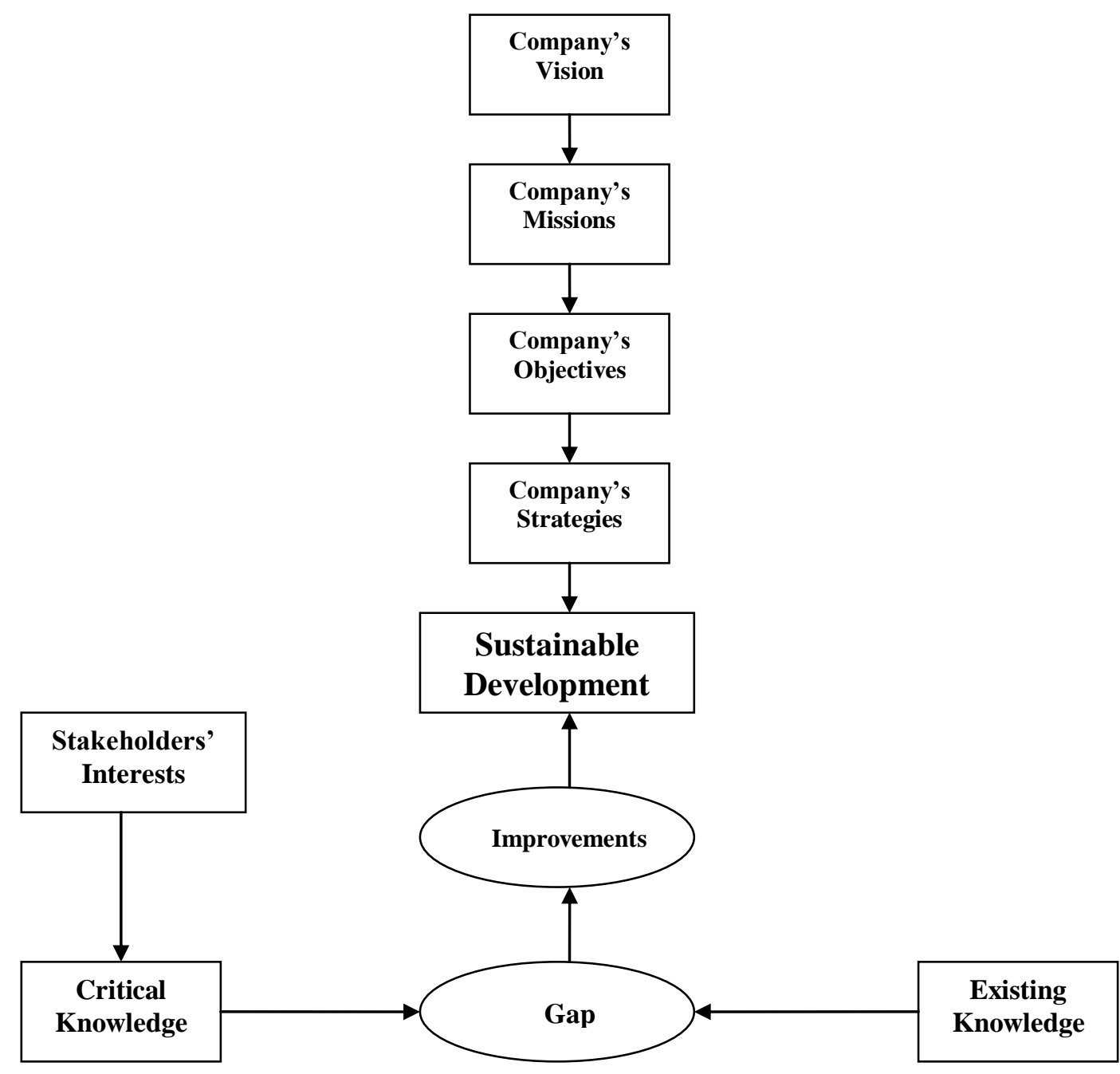

Knowledge management also has an important role to encourage a company's performance in knowledge-based economy era. Al-Hakim and Hassan (2011) state that through implementation of knowledge management, the organization will be able to survive, keep its stability and growth, then improve its performance. It is in accordance with the statement of Bennet and Bennet (2008). They 
mention that the collaborative involvement process among specialists and stakeholders does not simply help solve the current problems, but also keeps continuous improvement and sustainability in community.

\section{Conclusion}

In knowledge-based economy era, implementation of knowledge management is an absolute requirement needed by every company to survive. A company must be able to identify what its stakeholders' interests, then it must find out what critical knowledge required to meet those interests by reconciling its existing knowledge and the critical knowledge to fill the gap between them. Thus it can make relevant improvements integrated with its vision, missions, objectives, and strategies towards sustainable development to achive continuous performance improvement.

Recommendation: This study is conducted to present a linkage between the concepts of knowledge management and sustainable development. The conceptual models resulted by this study need to be improved and examined further through case study or other empirical research.

\section{References}

Al-Hakim, L. A. Y. \& Hassan, S. (2011). The Role of Middle Managers in Knowledge Managament Implementation to Improve Organizational Performance in the Iraqi Mobile Telecommunication Sector. Interdisciplinary Journal of Contemporary Research in Business, 3(5), 948-965.

Bennet, A. \& Bennet, D. (2008). The Fallacy of Knowledge Reuse: Building Sustainable Knowledge. Journal of Knowledge Management, 12(5), 21-33.

Blewitt, J. (2008). Understanding Sustainable Development. London: Earthscan.

Cheung, C. F., Li, M. L., Shek, W. Y., Lee, W. B. \& Tsang, T. S. (2007). A Systematic Approch for Knowledge Auditing: A Case Study in Transportation Sector. Journal of Knowledge Management, 11 (4), 140158.

Elkington, J. (1998). Cannibals with Forks. Gabriola Island: New Society.

Frederick, W. C., Davis, K. \& Post, J. E. (1988). Business and Society: Corporate Strategy, Public Policy, Ethics. New York: McGraw-Hill Publishing Company.

Gechev, R. (2005). Sustainable Development Economic Aspects. Indianapolis: University of Indianapolis Press.

Grayson, D. (2011). Embedding Corporate Responsibility and Sustainability: Marks \& Spencer. Journal of Management Development, 30(10), 1017-1026.

Ergazakis, K., Karnezis, K., Metaxiotis, K. \& Psarras, I. (2005). Knowledge Management in Enterprises: A Research Agenda. Intelligent Systems in Accounting, Finance and Management, 13, 17-26.

Krisnawati, A. (2013). Performance Measurement Systems of Corporate Social Responsibility. Postgraduate Business Colloquium. Naresuan University, Thailand.

Leydesdorff, L. (2006). The Knowledge Based Economy: Modeled, Measured, Simulated. Florida: Universal Publishers.

Maples, A. D. (2005). Sustainable Development New Research. New York: Nova Science Publishers.

March, J. \& Simon, H. (1958). Organizations. USA: John Wiley \& Sons, Inc.

Nguyen, H. N. and Mohamed, S. (2011). Leadership Behaviors, Organizational Culture and Knowledge Management Practices: An Empirical Investigation. Journal of Management Development, 30(2), 206-221.

Pirnea, I. C., Olaru, M. \& Moisa, C. (2011). Relationship between Corporate Social Responsibility and Social Sustainability. Economy Transdisciplinarity Cognition, 14(1), 36-43.

Robinson, H. S., Carillo, P. M., Anumba, C. J. \& Al-Ghassani, A. M. (2006). STEPS: a Knowledge Management Maturity Roadmap for Corporate Sustainability. Business Process Management Journal, 12 (6), 793-808.

Rooney, D. J., Hearn, G. N., Mandeville, T. \& Joseph, R. (2003). Public Policy in Knowledge-based Economies: Foundations and Frameworks. Cheltenham: Edward Elgar Publishing Limited.

Solomon, J. (2007). Corporate Governance and Accountability. West Sussex: John Wiley \& Sons Ltd.

Snyman, R. \& Kruger, C. H. (2004). The Interdependency between Strategic Management and Strategic Knowledge Management. Journal of Knowledge Management, 8 (1), 5.

Stewart, T. A. (1997). Intellectual Capital: The New Wealth of Organizations. London: Nicholas Brealey Publishing.

WCED. (1987). Our Common Future. New York: University Press. 
WCED. (2000). Korea and the Knowledge e-based Economy: Making the Transition: Information Society. Cedex: World Bank Institut, OECD. 